\title{
Perception of Teachers on their Preparedness for Implementation of the Competence-based Curriculum among Secondary Schools in Arumeru District, Tanzania
}

\author{
Daniel Kosia Mokoro \\ Tumaini University Makumira, Tanzania \\ *Corresponding author: danielkosia@yahoo.com
}

\begin{abstract}
The purpose of this study was to find out the extent to which implementation of competencebased curriculum $(C B C)$ is adequately supported by laboratory facilities among public secondary schools in Arumeru District, Tanzania, using a convergent parallel mixed design. Stratified-random sampling technique was used to select students and teachers whereas purposive sampling technique was used to select heads of schools and academic masters/mistresses. Consequently, the sample included 111 teachers, 177 students, 9 heads of schools and 9 academic masters/ mistresses making a total sample size of 306 respondents. Data were collected using questionnaires, interview guide, observation checklist and focus group discussion (FGD) guide and analyzed through descriptive statistics and thematic analysis. It was found that only $34 \%$ of the teachers were trained while $66 \%$ were not trained for $C B C$ implementation. The study concluded that, the implementation of $C B C$ is rendered ineffective due to lack of teacher training. The study recommended that the Ministry of Education, Science and Technology in collaboration with curriculum developers should organize training to all teachers for effective implementation of $C B C$.
\end{abstract}

Key words: Competence-based curriculum, implementation, teacher training, Meru District

\section{Introduction}

Studies conducted in Tanzania showed that the implementation of Competence-Based Curriculum (CBC) is faced by many challenges including teachers' reluctance to shift to the new paradigm of teaching, lack of in-service training to teachers regarding the $\mathrm{CBC}$, lack of knowledge and proper understanding of the $\mathrm{CBC}$ among teachers, lack of teaching and learning resources to implement the $\mathrm{CBC}$ and poor level of language proficiency on the part of some teachers and most students (Komba and Mwandanji, 2015; Makunja, 2016; Nyoni, 2018). Basically, these studies concluded that, the implementation of the curriculum in secondary schools is ineffective. Despite the existing studies in the country, none has been conducted in Arumeru District on the implementation of the competencebased curriculum in secondary schools so as to find out the status of teacher training regarding the $\mathrm{CBC}$ in the District. It is against this background that this study investigated on the extent to which teachers were trained for effective implementation of the CBC.

The $C B C$ in Tanzania is an innovation intended to enhance skills and competencies among the secondary school students. Although studies in the Tanzanian context have shown that the implementation of CBC is not effective, these studies mainly focused on the teaching approaches and most of them covered the tertiary and university level context (Paulo, 2014; Kavindi, 2014; Tambwe, 2017; Nzima, 2016). These studies revealed that, tutors are aware of $\mathrm{CBC}$ concepts but the classroom practice show the opposite whereby traditional teaching approaches are dominant in their lessons. In so far as CBC implementation in secondary schools is concerned, few studies such as Makunja (2016) and Komba and Mwandanji (2015) investigated on the implementation of $\mathrm{CBC}$ in public secondary schools in other regions within the 
country of Tanzania like Morogoro apart from that of Muneja (2015) which was conducted in Arusha region. Further, these studies employed case study designs with small samples, making the results not generalizable beyond the specific case context. While some studies in the country established that the implementation of $C B C$ is not effective, none of the reviewed studies were conducted in Arumeru District, yet the National Examination Council of Tanzania (NECTA) database shows relatively poor performance of public secondary schools in the District for the past four years whereby only $16.2 \%$ of the schools scored divisions 1 to 3 on average while $63.7 \%$ of private schools scored the same divisions on average (NECTA, 2018). This study therefore, sought to investigate on the extent to which teachers in Arumeru District were prepared for effective implementation of the CBC. The study was guided by the following three research questions:

1. What is the perception of teachers on their training regarding the Competence-based Curriculum?

2. What is the perception of teachers on the kind of training experienced on the Competence-based Curriculum?

3. What is the perception of teachers on the training in teaching methods recommended for Competence-based Curriculum?

The findings of this study are expected to inform concerned stakeholders and authorities such as quality assurance departments in the district regarding training teachers for effective implementation of the new curriculum reforms. The findings and recommendations can also be used as a basis for planning school based training to update teachers with required pedagogical skill. The study findings are also intended to inform teacher education programs at Teacher Training Colleges (TTCS) and universities so as to strengthen pedagogical issues among teacher trainees for effective implementation of the competence-based curriculum. The findings will also inform stakeholders on how better to train pre-service teachers for effective implementation of the Competence-Based Curriculum.

This study was confined to public secondary schools in the Arumeru District in Arusha Region. Public Secondary Schools were preferred due to the fact that Records from NECTA database indicates that the average academic performance of the public secondary schools is far lower compared to the private schools in the District (NECTA, 2018). The geographical area was further chosen because it is under-researched with respect to the implementation of the Competence-Based Curriculum. Furthermore, the choice of the public schools in Arumeru District was based on academic performance status which is low in form four national examinations with an assumption that lack of Competence-Based skills could have contributed to the problem.

\section{Literature Review}

Effective training of teachers is crucial for effective implementation of a curriculum. It is ideal that, before implementation of any new change, teachers are taken through training for updating them according to new curriculum demands. The training is therefore necessary to all teachers, new and experienced to equip them with knowledge and pedagogical skill for a successful implementation of the curriculum.

A similar study was conducted in Pakistan by Ali and Baig (2012) to identify reasons for delays in implementation of community oriented medical education (COME) curriculum. The authors assessed the understanding of stakeholders about the COME curriculum using a mixed method approach. Data were collected using in-depth interview through survey questionnaire and focus group discussions. The participants of the study included federal and provincial government representatives, principals, faculty and students from medical colleges. The results of the study revealed that most teachers felt that they had not been adequately trained on problem based learning while the school administrators showed the opposite. Majority of Faculty members (65\%) mentioned that most teachers were not trained. In addition, $55 \%$ of respondents stated frequent transfers of faculty members from one institution to another resulted into faculty turn over which affected the quality of teaching and thus a need for continued faculty training activities. That study however, did not describe how the subjects were selected and sampling procedures used. The study also was biased on medical field in tertiary education, whose requirements may be different from those of the general educational field in secondary schools. In response to this gap, this study ensured that, the methodology and procedure employed were well explained for appropriate possible repeatability, just in case of the need to do so. 
Rahman (2018) explored the factors affecting teachers' implementation of Communicative Language Teaching (CLT) Curriculum among secondary schools in Bangladesh, using the phenomenology design. Sample of the study included four schools where two came from urban and two came from rural areas. The participants of the study were eight, selected using purposive sampling method. Data were collected using interviews, classroom observation and document analysis. The findings show that teachers were poorly oriented to the CLT curriculum; hence they found it hard to understand the materials even though most of the elements were adopted from the western context which was unfamiliar in Bangladesh. Furthermore, it was reported that, the only professional support teachers in Bangladesh received was teacher training. However, the adequacy and effectiveness of the training was questioned especially among rural school teachers. The training was said to depend on availability of trainers and programs and respondents expressed that, the teacher training provided minimal information regarding the CLT methods and practice.

Based on those findings, it was necessary to do a similar study in the context of Tanzania to determine how the training of teachers took place prior to the implementation of the CBC. This study ensured that various groups of respondents are included to incorporate perspective of different stakeholders and also mixed methods research design was employed so as to overcome the weakness of designs used in previous studies.

Another investigation was done by Suyanto (2017) on schools readiness to implement the new 2013 curriculum in Indonesia. The study intended to find out problems in curriculum implementation due to the assumption that the implementation was a setback to the previous school based curriculum for most schools. The research design used by the study was survey which involved 33 junior high schools from seven regencies in the country. The participants included 33 principals and vice principals for curriculum affairs though the sampling techniques for selection were not stated. Data were collected using instruments such as questionnaires, interview guides, observation checklists and rubrics. The study established that one of the factors for schools readiness to curriculum implementation was related to teachers training. The findings of the study further showed that among the schools studied, only $33 \%$ of the teachers got trained on the implementing the new curriculum. In addition, it was revealed that, only $37 \%$ of the teachers had good understanding on the new curriculum. The study also reported that teachers had difficulties in various areas such as lesson development (16\%), using scientific approach (31.5\%) and implementing authentic assessment procedures (43.5\%). It was also found that majority of students (78.5\%) reported that learning through the new curriculum was more difficult than learning through the former curriculum. That study concluded that, the main reason for low readiness of the schools in implementing the 2013 curriculum was ineffective training of teachers, school principals and supervisors. Given this situation, the curriculum cannot be successfully implemented as various aspects such as teaching activities, learning activities and assessment activities were not done well due to lack of appropriate skills.

A study by Lumadi (2014) explored on factors faced by teachers in curriculum implementation in South African context. The study identified that various external factors impacted negatively on curriculum implementation. The factors included: technical jargon, training, haphazard changes, job security and time. Looking at the identified factors, the haphazard changes and training relate to teacher preparation for the implementation of the new curriculum. Majority of teacher respondents (69\%) complained about sporadic changes in curriculum which rendered ineffectiveness in curriculum implementation. Also, majority (53\%) of teachers complained that they did not receive enough inservice training for curriculum implementation. They also mentioned that most teachers in rural schools received 3-5 days training and some teachers considered this as an inferior type of training and some went further to resigning. Finally, teachers opined that the training should be detailed and prolonged to a period of one year prior to curriculum implementation.

In the South African context, Govender (2018) explored teachers' perspectives on implementing curriculum reforms in schools in U-Thungulu District, Kwa Zulu Natal. It aimed at ascertaining challenges that faced the process and the kind of support, guidance and professional development programme teachers received from the Basic Education Department to facilitate the changes. This study used an interpretive qualitative research design. A sample of 20 teachers of grades one to six was 
purposively selected and data were collected using semi-structured interviews. Data were analyzed using content and thematic analysis approach. The participants expressed discontent about quantity and quality of training workshops offered by the Department of Basic Education to support the curriculum change. The participants further mentioned that the training was a one day workshop and there was no further in-service training provided (i.e. no continuous professional development programmes were in place). Therefore, the inadequate training and preparation of teachers in implementing new curriculum renders teachers' ineffectiveness in the curriculum implementation process.

In Baringo North Sub County, Kenya, Kimosop (2019) conducted a study to investigate how pre-school teachers are prepared to teach curriculum in public learning institutions. This study employed a descriptive survey design and a sample comprised of 72 pre-school teachers selected using convenience sampling, 36 head teachers and 1 Sub-County Director. The study found that majority of respondents (94\%) were not prepared before the implementation of the ECDE curriculum prior to the introduction of ECDE curriculum in the year 2008. The study further established that seminars were offered in rare cases before the curriculum implementation. Other researchers (Migosi, Misia \& Paul, 2016) conducted a study to establish the influence of teacher related factors on the implementation of physical education curriculum in primary schools in the country. The design used was descriptive survey and the participants included 28 head teachers, 138 teachers and 4 zonal quality assurance and standards officers (ZQASO) selected using simple random and purposive sampling methods. The findings showed that majority of teachers were not adequately prepared for the implementation of physical education syllabus. In connection to the findings, responses from teachers showed that majority (62\%) of them never prepare schemes of work and lesson plans, hence lack of seriousness by teachers on professional procedures in teaching physical education subject.

In the context of Tanzania, Makunja (2015) carried out a study to assess the adoption of competence based curriculum $(C B C)$ to improve the quality of secondary schools in Morogoro Region. This study employed a descriptive survey design and 162 respondents were involved from 6 public secondary schools. The participants were selected using purposive and simple random sampling procedure. They included 6 heads of schools, 6 academic masters, 102 teachers and 48 students. Data were collected using questionnaires, interviews and observations and were analyzed using descriptive statistics and content analysis. The findings of the study showed that some teachers 46 (45.1\%) did not understand the $\mathrm{CBC}$ which they participate in its implementation. The study also revealed that majority of teachers $(73 \%)$ did not get any training before the implementation of the CBC. Furthermore, majority of teachers (60.78\%) confessed that they did not have ability to apply the competence based teaching approach in the teaching and learning process.

Furthermore, Makunja (2016) investigated about challenges facing teachers in implementing $C B C$ in secondary schools in Morogoro region in Tanzania. The study employed a case study research design. The sample composed of 102 teachers, 6 heads of schools and 6 academic masters/mistresses. Data collection was done using questionnaire, interviews and analysis was done using content analysis. The study found that teachers were faced by challenges such as lack of in-service training on $C B C$, insufficient teaching and learning resources, overcrowded classrooms, low ability of students joining secondary schools and students' readiness to accept the learner center approach.

A study conducted by Lukindo (2016), explored the implementation of $C B C$ in rural secondary schools in Tanzania using a qualitative methodology. The findings revealed that the respondents were not sure whether their teaching and assessment techniques were in line with competence based education. A study by Paulo (2014) investigated on pre-service teacher's preparedness to implement the competence based curriculum for secondary schools. This study involved 16 pre-service teachers from the university of Dar salaam who were in the teaching practice. The study established that the pre-service teachers were aware of the $C B C$ teaching and assessment methods but they were not adopting these methods in their classrooms practice. As a result, this study therefore sought to find out whether teachers were trained in specific teaching methods as recommended by the competence-based curriculum.

Likewise, Komba and Mwandanji (2015) examined the issues surrounding the implementation of the CBC in secondary schools located in Morogoro 
Region. The design used was a case study and the sample composed of 180 teachers selected randomly from 13 Secondary Schools. The study found out that majority of teachers (86\%) did not have proper understanding of the $\mathrm{CBC}$ objectives. Majority of lesson plans (78\%) did not reflect qualities of $C B C$ and the involvement of learning in classroom activities was very low.

Though many studies done in Tanzanian context mentioned that teachers lacked training, they did not investigate on the specific teaching methods recommended in the competence based curriculum for ordinary secondary schools. This study addressed the gap by investigating on the teacher training in the specific teaching methods demanded by the $\mathrm{CBC}$. The methods include, problem solving, practical skill, demonstration, project, library search, online search, case analysis, debates, group discussion and group reporting and presentation.

\section{Methodology of the Study}

The study adopted a mixed-method design known as convergent parallel design. This is a single-phase approach where the researcher collects both quantitative and qualitative data, analyzes them separately then compares to see if the findings confirm or disconfirm each other (Creswell \& Creswell, 2018). The convergent parallel design enables the researcher to triangulate the methods by directly comparing and contrasting quantitative statistical results with qualitative findings for corroboration and validation purposes (Creswell \& Clark, 2011). The convergent parallel design was preferred as it allowed the collection of both quantitative data and qualitative data for corroboration purposes. The mixed method design helps to address the weakness of each design; hence the designs complement each other.

\section{Population and Sampling}

Population is a larger group to which one hopes to apply the results (Fraenkel, Wallen \& Hyun, 2015). The study had a population consisting of heads of schools, academic masters/mistresses, teachers and students. The heads of schools and academic masters/mistresses population was 35 for each group while the teachers' population was 1193 . The students' population was 7387 . Heads of schools and academic masters/mistresses were sampled using purposive sampling technique. Both teachers and students were selected using stratified sampling technique. The sample included 9 heads of schools,
9 academic masters/mistresses, 111 teachers and 177 students making a total sample size of 306 .

\section{Data Collection}

Data was collected using multiple research instruments to different groups of respondents. The Questionnaires was used to collect data from teachers and students. The instruments had both closed-ended and open-ended items as the study targeted to collect both quantitative and qualitative data. Qualitative data was collected using semistructured interview guides and the focus group discussion (FGD) guides with heads of schools and teacher respectively.

\section{Findings and Discussion}

The study investigated extent to which teachers were trained for effective implementation of CBC. Particularly, the study sought to establish whether teachers were trained, the kind of training and the length of training. Further the study targeted on establishing whether teachers were trained in specific teaching and assessment methods required by the CBC. The study was guided by three research questions as follows:

Research Question 1: What is the perception of teachers on their training regarding the Competence-based Curriculum?

With regard to whether teachers were trained for effective implementation of $\mathrm{CBC}$, the findings are presented in Table 1.

\begin{tabular}{|c|c|c|}
\hline Trained in $\mathrm{CBC}$ & Frequency & percentage \\
\hline Yes & 34 & 34 \\
\hline No & 66 & 66 \\
\hline Total & 100 & 100 \\
\hline
\end{tabular}

Table 1 shows that a majority (66\%) of teachers were not trained in the CBC while only $34 \%$ indicated that they were trained. The lack of training is likely to affect teacher's competency in implementing the current curriculum. Similar finding had been reported by Lumadi (2014) in South Africa that, $53 \%$ of teachers complained that they did not receive adequate training for curriculum implementation. The findings are also in harmony with those by Makunja (2015) which showed that majority of teachers (75\%) in secondary schools in Morogoro did not receive any training before the implementation of the competence-based curriculum. 
Research Question 2: What is the perception of teachers on the kind of training experienced on the Competence-based Curriculum?

The study sought to establish about the mode of training that teachers had received for implementation of the CBC. This was achieved by asking teachers on the kind of training that they got for the implementation of the curriculum as reflected in Table 2.

Table 2: Kind of Training on CBC Implementation

\begin{tabular}{lcc}
\hline Training attained & Frequency & percent \\
\hline Pre-service & 4 & 11.8 \\
In-service & 8 & 23.5 \\
Seminars & 22 & 64.7 \\
Total & $\mathbf{3 4}$ & $\mathbf{1 0 0}$ \\
\hline
\end{tabular}

According to Table 2, most teachers were trained through seminars (64.7\%). Others received knowledge through in-service training (23.5\%) and a few $(11.8 \%)$ received the training through the pre- service programmes. Through the interview with heads of school and FGD, it was revealed that, most seminars the teachers attended were through projects run by some nearby universities as part of community service in secondary schools. The finding is different from that of Jerotich, Kurgat and Kimutai (2017) in Kenya who revealed that, teachers had not received any in-service training in terms of seminars and workshops for implementation of integrated Business Studies Curriculum in public secondary schools.

Research Question 3: What is the perception of teachers on the training in teaching methods recommended for Competence-based Curriculum?

This section established whether teachers were trained in specific teaching methods as recommended for the competence-based curriculum as reflected in Table 3.

Table 3: Training in Teaching Methods Recommended for CBC

\begin{tabular}{lcccc}
\hline & \multicolumn{2}{c}{ Trained } & \multicolumn{2}{c}{ Not trained } \\
\cline { 2 - 5 } Teaching methods & Frequency & Percentage & Frequency & Percentage \\
\hline Problem solving & 49 & 49.5 & 50 & 50.5 \\
Demonstration & 50 & & 49 & 49 \\
Technical/Laboratory skill & & 25 & 72 & 75 \\
& 24 & 33.3 & 66 & 66.7 \\
Debates & 33 & 64 & 36 & 36 \\
Group discussions & 64 & 57 & 43 & 43 \\
Group reporting and & 57 & 37 & 63 & 63 \\
presentation & 37 & 27.6 & 71 & 72.4 \\
Case analysis & 27 & 26.5 & 72 & 73.5 \\
Library searches & 26 & & & \\
Online searches & & & & \\
\hline
\end{tabular}

Problem solving is among the competencies the CBC requires learners to acquire. As shown in Table 3, there were almost equal proportions of trained (49.5\%) and untrained (50.5\%) teachers in problem solving teaching method. The established lack of training in this method by slightly more than a half of respondents may make the teachers incompetent in using it and therefore depriving learners form acquiring the problem solving skills in schools.

Among the teachers who participated in the study, $49 \%$ were not trained in the demonstration method of teaching. However, through FGD, it was revealed that, demonstration was common due to inadequacy of laboratory supplies. Another method in Table 3 is technical or laboratory skills method of teaching. Data show that, a majority (75\%) of the respondents were not trained in that teaching method. Through the observation schedule in the studied schools, the study also established that none of the schools had a laboratory technician, which might be the reason for lack of training. With regard to debate method, only $33.3 \%$ of the teachers reported that they were trained while a high proportion of teachers were not trained $(66.7 \%)$ on the method. The lack of training in debate method may make teachers less skilled in imparting and enhancing to learners important skills related to debates. The skills include oral expression, speech making, argumentation and critical thinking among other skills, which contribute to effective communication skills among the learners.

Table 3 further shows that, most teachers (64\%) were trained in group discussion method. This 
makes teachers effective in organizing group discussions in the teaching and learning process. Discussion is important in the teaching and learning process as it enables learners to share ideas in learning the subject matter. Further, it enables learners to contribute to the lesson instead of the teacher dominating the classroom sessions. The method also fosters the acquisition of other skills and values such as collaboration, communication, and leadership in the groups.

The data also show that above fifty percent of the teachers $(57 \%)$ were trained in group presentation and reporting. On the other side, a number of teachers (43\%) were not trained in this method. The method requires students to learn to make presentations in class during the teaching and learning process and writing the reports on some assignments. The established lack of training by the minority may deprive learners of acquiring and developing presentations ability and reporting skills. This method of teaching makes learners become self-directed and autonomous in learning. Therefore it is important to make sure that teachers are trained on this approach.

Another method shown in Table 3 is case analysis. Data shows that, a majority of teachers (63\%) were not trained in case analysis method. This may lead to teachers' failure to impart the analysis skills to students in secondary schools. While the $C B C$ requires that learners should be able to analyze materials including texts in learning, lack of training in case study method may lead students to miss the critical thinking skills which are among the competence-based targets.

Data in Table 3 show that, a majority of teachers (72.4\%) were not trained in library searches method. This deficiency in training suggests a possibility that teachers may not consider library search as an important method of teaching and learning in secondary schools even though the library search method gives learners an opportunity to explore and use library resources to enrich their learning. The method further enables learners to contribute significantly in their education through discovery of knowledge, hence enhancing constructivism.

A majority of teachers (73.5\%) reported that they were not trained in online search method of teaching. While the current secondary education curriculum recommends this method to be used in secondary schools, this finding implies a possibility that teachers are less skilled in online technology, thus it is not incorporated in the teaching and learning process. This shortcoming may also be influenced by lack of ICT facilities and resources in secondary schools. Consequently, learners miss the opportunity to acquire and practice the online search skills in their learning process.

\section{Conclusions and Recommendations}

This part gives conclusions of the study and then comes up with corresponding recommendations to various education stakeholders.

\section{Conclusions of the Study}

The study concludes that a good number of teachers were trained in some of the recommended teaching methods for Competence-based Curriculum such as demonstration, group discussions and reporting and presentation. However, a number of teachers were not adequately trained on the $\mathrm{CBC}$ as the training was mainly in the mode of seminars which were run for a short time. Therefore, teachers are not adequately prepared in terms of training for the implementation of the competence-based curriculum in secondary schools. Particularly, a number of teachers were not trained in various recommended teaching methods like problem solving, technical skill, debates, case analysis, library searches and online searches. Since teachers seem not to be trained in various recommended methods for the $\mathrm{CBC}$, this condition reduces the variation of teaching styles which would make learners more involved and engaged in various ways for effective learning and developing different competencies as targeted by the $\mathrm{CBC}$. Therefore, teachers are rendered less competent methodologically in implementation of the competence based curriculum due to inadequate training for the curriculum demand.

\section{Recommendations of the Study}

Based on conclusions of this study, it is recommended that the Ministry of Education, Science and Technology in collaboration with curriculum experts/developers should organize for pedagogical training sessions to teachers in secondary schools in Meru District to equip them with the methodological competencies in using different teaching methods as demanded by the competence-based curriculum. The study also recommends that, there is a need for the Meru District Council in collaboration with the Ministry of Education, Science and Technology to organize for 
an ongoing program to update teachers on skills required for appropriate teaching in the context of competence based curriculum. Other educational stakeholders need to collaborate with the government in facilitating educational service including updating teachers' pedagogical skills. The local government through the District Council should have plans for continued training of teachers for effective implementation of the CBC. One way to accomplish this task may be through empowering heads of schools to organize school-based regular in-service training programs for teachers' induction.

\section{Reference}

Ali, S. K \& Baig, L. (2012). Problems and Issues in implementing innovative curriculum in developing countries: the Parkistan experience. Parkistan: BMC.

Creswell, J. W. and Creswell, J. D. (2018). Research Designs: Qualitative, Quantitative \& Mixed Methods Approaches (5 $5^{\text {th }}$ Ed.). London: SAGE Publications.

Creswell, J. \& Clark, P. (2011). Designing \& Conducting MMR. Thousand Oaks: SAGE

Fraenkel, J.R, Wallen, N.E., and Hyun, H.H. (2015). How to Design and Evaluate Research in Education ( $9^{\text {th }}$ Ed.). New York: McGraw-Hill Education.

Govender, S. (2018) South African teacher's perspectives on support received in implementing curriculum changes. South African Journal of Education. 38 (2), 1-12.

Jerotich, F., Kurgat. S. J. and Kimutai C. K.(2017). Teacher Preparedness in the Implementation

of the Integrated Business Studies Curriculum in Public Secondary Schools in Kenya. Journal of Education and Practice, 8 (14), 105-111.

Kavindi, A.E. (2014). The Implementation of Competence Based Curriculum in Certificate Teachers

Colleges in Tanzania: The Case of Two Teachers Colleges in Mbeya Region. Med Thesis. University of Oslo
Kimosop, H. (2019). Teacher Preparedness in the Implementation of Early Childhood Education Development Curriculum in Kenya: A case of Baringo North Sub-County, Kenya. IOSR Journal of Humanities and Social Science, 24 (2), 44-50.

Komba, C.S. \& Mwandanji M. (2015) Reflection on the implementation of Competence Based Curriculum in Tanzanian secondary schools. Journal of Education and Learning; 4 (2) 7380

Lukindo, J.J. (2016). Exploring Competence Based Education in Rural Secondary Schools in Tanzania: English Languaje Teachers Conceptions and Experinces. Journal of Education and Practice. 7 (29) 62-67.

Lumadi, W.M. (2014) Exploring Factors Faced by Teachers in Curriculum Implementation. Mediterranean Journal of Social Sciences, 5 (6) 171-178.

Makunja, G. (2015). Adopting Competence -Based Curriculum to Improve Quality of Secondary Education in Tanzania: "Is it a Dream or Reality"? International Journal of Education and Research, 3 (11), 185-188.

Makunja, G. (2016). Challenges Facing Teachers in Implementing Competence-Based Curriculum in Tanzania: The Case of Community Secondary Schools in Morogoro Municipality. International Journal of Education and Social Science,3 (5), 30-37

Migosi, Z., Misia, K. \& Paul, M. (2016). Influence of Teacher Related Factors on the Implementation of Physical Education Syllabus in Public Primary Schools in Manga Sub-County, Kenya. International Journal of Education and Research, 4 (9), 1-18.

Muneja, M. S. (2015). Secondary School Teachers Implementation of the Competence Based Curriculum in Arusha Region, Tanzania. University of South Africa

NECTA (2018). Ranking of District Councils based on Certificate of Secondary Education Examination Results. Dar es Salaam: MoEST. 
Nyoni, Z .K. (2018) Challenges Facing Teachers in Tanzania: the implementation of the paradigm shift towards a competence-based curriculum in public secondary schools in Iringa municipality. Kervan-International Journal of Afro-Asiatic studies, 1 (22), 195215.

Nzima, I. (2016). Competence- Based Curriculum (CBC) in Tanzania: Tutors' Understanding and their Instructional Practices. Doctoral Dissertation. Linneaus: Linneaus University Press.

Paulo, A. (2014). Pre-service Teachers Preparedness to Implement Competence Based Curriculum in Secondary Schools in Tanzania. International Journal of Education Research. 2 (7), $219-230$.
Rahman, M.M. and Pandian, A and Kaur, M. (2018) Factors Affecting Teachers Implementation of Communicative Language Teaching Curriculum in Secondary Schools in Bangladesh, The qualitative Report. 23 (5) 1104-1126.

Suyanto, S. (2017). A reflection on the Implementation of $A$ New Curriculum in Indonesia: A crucial problem on School Readiness .Indonesia: AIP Publishing.

Tambwe, M. A. (2017). Challenges facing implementation of Competence -Based Education and Training (CBET) system in Tanzanian Technical Institutions. Education Research Journal, 7(11), 277-283. 